\title{
Effects of Mutations in the Human Uncoupling Protein 3 Gene on the Respiratory Quotient and Fat Oxidation in Severe Obesity and Type 2 Diabetes
}

\author{
George Argyropoulos, ${ }^{\star}$ Angela M. Brown, ${ }^{\star}$ Steven M. Willi, ${ }^{\ddagger}$ Jianguo Zhu, ${ }^{\star}$ Yufang He, ${ }^{\S}$ Marc Reitman, ${ }^{\S}$ Sahr M. Gevao," \\ Ida Spruill, ${ }^{*}$ and W. Timothy Garvey* \\ *Department of Medicine, Division of Endocrinology, ${ }^{\ddagger}$ Department of Pediatrics, Medical University of South Carolina and the Ralph H. \\ Johnson Veterans Affairs Medical Center, Charleston, South Carolina 29425; ${ }^{\circledR}$ Diabetes Branch, National Institute of Diabetes and \\ Digestive and Kidney Diseases, National Institutes of Health, Bethesda, Maryland 20892-1770; "College of Medicine and Allied Health \\ Sciences, University of Sierra Leone, Freetown, Sierra Leone
}

\begin{abstract}
Human uncoupling protein $3(U C P 3)$ is a mitochondrial transmembrane carrier that uncouples oxidative ATP phosphorylation. With the capacity to participate in thermogenesis and energy balance, $U C P 3$ is an important obesity candidate gene. A missense polymorphism in exon 3 (V102I) was identified in an obese and diabetic proband. A mutation introducing a stop codon in exon 4 (R143X) and a terminal polymorphism in the splice donor junction of exon 6 were also identified in a compound heterozygote that was morbidly obese and diabetic. Allele frequencies of the exon 3 and exon 6 splice junction polymorphisms were determined and found to be similar in Gullah-speaking African Americans and the Mende tribe of Sierra Leone, but absent in Caucasians. Moreover, in exon 6-splice donor heterozygotes, basal fat oxidation rates were reduced by $50 \%$, and the respiratory quotient was markedly increased compared with wild-type individuals, implicating a role for $U C P 3$ in metabolic fuel partitioning. (J. Clin. Invest. 1998. 102:13451351.) Key words: $U C P 3 \cdot$ mutation • obesity • fat oxidation • respiratory quotient • African American
\end{abstract}

\section{Introduction}

Human uncoupling protein $3(U C P 3)^{1}$ is a recently identified gene that encodes a mitochondrial transmembrane carrier protein and shows high amino acid similarities with the other two human uncoupling proteins, UCP1 and UCP2 (57\% and 73\%, respectively) (1-3). UCP1 plays an important thermogenic role in brown adipose tissue by virtue of its capacity to uncouple mitochondrial respiration from oxidative phosphorylation in a regulated manner (4). The $U C P 1$ gene has been mapped to chromosome $4 \mathrm{q} 31$ and is comprised of six coding exons (5). The two new members of this family, UCP2 and UCP3, have

Address correspondence to George Argyropoulos, Ph.D., Division of Endocrinology, Department of Medicine, Medical University of South Carolina, 171 Ashley Avenue, Charleston, SC 29425. Phone: 843-953-6443; FAX: 843-953-6444; E-mail: argyrog@musc.edu

Received for publication 27 May 1998 and accepted in revised form 12 August 1998.

1. Abbreviations used in this paper: $\mathrm{BMI}$, body mass index; FFA, free fatty acid; PNBD, purine-nucleotide-binding domain; RQ, respiratory quotient; $U C P 3$, uncoupling protein 3 .

J. Clin. Invest.

(C) The American Society for Clinical Investigation, Inc. 0021-9738/98/10/1345/07 \$2.00

Volume 102, Number 7, October 1998, 1345-1351

http://www.jci.org also been shown to function as mitochondrial uncouplers $(2$, 6). Unlike $U C P 1, U C P 2$ is widely expressed (6), whereas $U C P 3$ is predominantly expressed in skeletal muscle $(1,7)$, a major tissue contributing to non-shivering thermogenesis in humans (3). UCP2 and UCP3 have been localized within 150 $\mathrm{kb}$ of each other on chromosome 11q13 $(2,7)$. Both UCP2 and $U C P 3$ genes consist of six coding exons $(7,8)$, with each exon encoding a putative transmembrane spanning region and at least one upstream non-coding exon. UCP3 encodes two forms of transcripts: the full-length message designated $U C P 3_{\mathrm{L}}$ and $U C P 3_{\mathrm{S}}$, which truncates before the sixth coding exon via use of an alternative polyadenylation site (7).

As an uncoupler of oxidative phosphorylation, UCP3 has the potential to play an important role in energy balance and determination of body weight. Accordingly, UCP3 has been shown to be regulated by thyroid hormone, $\beta_{3}$-adrenergic agonists, leptin, and fat feeding in rodents $(2,9,10)$. In the mouse, brown adipose tissue appears to be an important regulator of high fat diet-induced obesity, possibly mediated by $U C P 1$ and $U C P 2$ (11). In humans, significant linkage has been reported between markers at the $U C P 2 / U C P 3$ gene locus with resting metabolic rate (D11S911, $P=0.000002$ ) (12). This region is syntenic to a region of mouse chromosome 7 that has been linked to hyperinsulinemia and obesity (6). Thus, UCP3 is a new compelling candidate gene for human obesity. To date, the only reported genetic defects directly associated with human obesity have been congenital leptin deficiency $(13,14)$ caused by a frameshift mutation in two related children (15), another leptin missense mutation associated with hypogonadism (16), and mutations found in the human prohormone convertase-1 gene (17). In this study, UCP3 was examined as a candidate gene for obesity/diabetes and its coding exons were investigated for possible presence of mutations/polymorphisms that could contribute to the development of obesity and/or diabetes.

\section{Methods}

Subjects and clinical characteristics. The study was approved by the Institutional Review Boards at the Medical University of South Carolina and the University of Sierra Leone, and all participating individuals gave informed consent. Type 2 Diabetes Mellitus status was established according to the National Diabetes Data Group (18) or by measuring glycosylated hemoglobin levels (19). Body Mass Index (BMI) is the body weight $(\mathrm{kg})$ divided by height $\left(\mathrm{m}^{2}\right)$. Respiratory calorimetry, energy expenditure, resting metabolic rate, percent body fat, cholesterol levels, fat oxidation, and lean body mass were measured as previously described (20). Statistical analyses were performed using Statistica for Windows, version 5.1 (Statsoft, Inc., Tulsa, OK).

Amplification of genomic DNA and sequence determination. For $U C P 3$ gene sequence determination, genomic DNA was isolated from peripheral blood using a standardized DNA isolation kit (Gentra Systems, Minneapolis, MN). DNA was also isolated from filter-dot-blotted 
blood drops also using a standardized DNA isolation kit (Gentra Systems). In Sierra Leone, DNA was isolated from $3 \mathrm{ml}$ of peripheral blood collected locally from volunteers of the Mende tribe residing in the District of Kenema. The polymerase chain reaction (PCR) was employed to generate sequencing templates comprising the entire coding region of the $U C P 3$ gene. PCR and sequencing primers were designed, as previously described (8), using the $U C P 3$ cDNA sequence with GenBank Accession number U84763. A $6.5 \mathrm{~kb}$ PCR product was generated by long PCR (Boehringer Mannheim, Indianapolis, IN) using the following primer pair: 94f: 5'-AGCAGCCTCTCTCCTTGGACCTC-3' and 1161r: 5'-GATGCACCGTTTTCTTCCAT-3'. The following primers were used to obtain bidirectional DNA sequences: exon 2: $94 f$ and UCP3e2r: 5'-TGTCAGGGTTCTGAGGAAGG-3'; exon 3: UCP3e3f: 5'-TGACCAGCATGGTTGTTCTA-3' and UCP3e3r: 5'-CCTGGTCTGCCTCTGAGTCT-3'; exon 4: UCP3e4f: 5'-ATGAGGAGGCTCTGAGTGGA-3' and UCP3e4r: 5'-TCAGAATCACTGGAACACGC-3'; exon 5: UCP3e5f: 5'-GCACTATGGCCCCAAAACT-3' and UCP3e5r: 5'-CTTTCCTGCTTGTCACCACA-3'; exon 6: UCP3e6f: 5'-GGGCACTGTGAGAGATATGGA-3' and UCP3e6r: 5'-CAGCTGACCCACGGTAG-3'; exon 7: UCP3e7f: 5'-AAAGGATTCAGAAAATGCTTGTG- $3^{\prime}$ and $1161 r$.

DNA sequence determinations were performed using an ABI 373 automated sequencer (Perkin Elmer, Foster City, CA). Mutations and polymorphisms were confirmed by manual sequencing using a standardized commercial kit (Perkin Elmer, Foster City, CA). All sequence assembly and manipulations were conducted using the GeneWorks software (IntelliGenetics Inc., Mountain View, CA) and the Baylor College BCM Search Launcher at: http://gc.bcm.tmc.edu: 8088/search_launcher/launcher.html.

Mutation screening: amplification and restriction digest of exons 3, 4, and 6. The following primers were used to amplify genomic DNA and generate a $376 \mathrm{bp}$ PCR product containing the V102I polymorphism: $U C P 3 e 3 f b$ : 5' -CCAGCAGGGTTCCTGTGC-3' and $U C P 3 e 3 r$. Taq DNA polymerase was purchased from GIBCO-BRL (Gaithersburg, MD) or QIAGEN (Santa Clarita, CA) and PCR conditions were set as prescribed by the manufacturers (at $1.5 \mathrm{mM} \mathrm{MgCl}_{2}$ ). Reaction samples $(15 \mu \mathrm{l} \mathrm{each})$ were denatured for $3 \mathrm{~min}$ at $95^{\circ} \mathrm{C}$ and PCR was performed for 35 cycles, each cycle consisting of three segments; $95^{\circ} \mathrm{C}$ for $30 \mathrm{~s}, 55^{\circ} \mathrm{C}$ for $45 \mathrm{~s}$, and $72^{\circ} \mathrm{C}$ for $60 \mathrm{~s}$. An additional extension period of $5 \mathrm{~min}$ at $72^{\circ} \mathrm{C}$ was applied upon completion of the 35 cycles. All PCR reactions were performed in a 9600 thermal cycler (Perkin Elmer). To determine the V102I polymorphism, the above PCR products were directly digested with Tth111 I restriction endonuclease, as prescribed by the manufacturer (New England Biolabs, Beverly, MA), in $20-\mu \mathrm{l}$ volumes, for $2 \mathrm{~h}$ at $65^{\circ} \mathrm{C}$. Digested PCR products were loaded on to $4 \%$ agarose gels and visualized with ethidium bromide $(0.5 \mu \mathrm{l} / \mathrm{ml})$ under UV light. Restriction digestion of the 376-bp PCR product with Tth111 I results in the following fragments: $G / G$ homozygotes, 249, 81, and $46 \mathrm{bp}$; and $A / A$ homozygotes, 295 and 81 bp. To detect the R143X mutation, exon four was amplified with primers $U C P 3 e 4 f$ and $U C P 3 e 4 r$, and the $436 \mathrm{bp}$ PCR product was digested with $A v a I I$ enzyme at $37^{\circ} \mathrm{C}$ for $2 \mathrm{~h}$, resulting in the following fragments: $C / C$ homozygotes, 202,184 , and $50 \mathrm{bp}$; and $T / T$ homozygotes, 386 and $50 \mathrm{bp}$. To detect the exon 6-splice donor-stop polymorphism, exon 6 and flanking intronic sequences were amplified with primers UCP3e6f and UCP3e6r. The resultant 396-bp PCR product was digested with Fok $I$ enzyme at $37^{\circ} \mathrm{C}$ for $2 \mathrm{~h}$ and examined in $4 \%$ agarose gels. The splice junction polymorphism introduces a restriction site for Fok I, resulting into two fragments of 316 and $80 \mathrm{bp}$.

\section{Results}

To determine whether UCP3 mutations could contribute to human obesity, the nucleotide sequence of all six coding exons was determined in 40 sequentially recruited subjects, comprising 20 severely obese and diabetic African Americans, 10 diabetic and/or obese Caucasians, and 10 controls (lean and non- diabetic). For sequence analyses, a $6.5-\mathrm{kb}$ fragment containing all six coding exons of the gene was generated by long PCR. Bidirectional sequences from each exon were aligned and compared with the coding regions and splice junctions of the UCP3 gene (GenBank Accession numbers: U84763, AF011449, and AF012202). This approach revealed one mutation and two polymorphisms in two probands with severe obesity and diabetes; Fig. 1 delineates the mode of transmission in nuclear families. All mutations detected were confirmed by manual sequencing (Fig. 2). A G304A polymorphism in exon 3 was first identified in the heterozygous mother with severe obesity and diabetes, and resulted in a conservative amino acid substitution of a valine by an isoleucine at residue 102 (V102I) in the first cytosol-orientated extramembranous loop (Fig. 3). Family members were recruited, and sequence determination in the three overweight children (BMIs of 44.7, 29.2, and 26.1) showed that they were homozygous for the V102I polymorphism (Fig. $1 A$, individuals 3, 4, and 5). The fourth child was a 9-yr-old male with a BMI of 18.5 and was heterozygous for the V102I polymorphism. No paternal sample was available, but it is likely that the father was at least heterozygous for the V102I polymorphism.

The V102I polymorphism in exon 3 was amplified from genomic DNA in 128 Caucasian Americans but was not detected
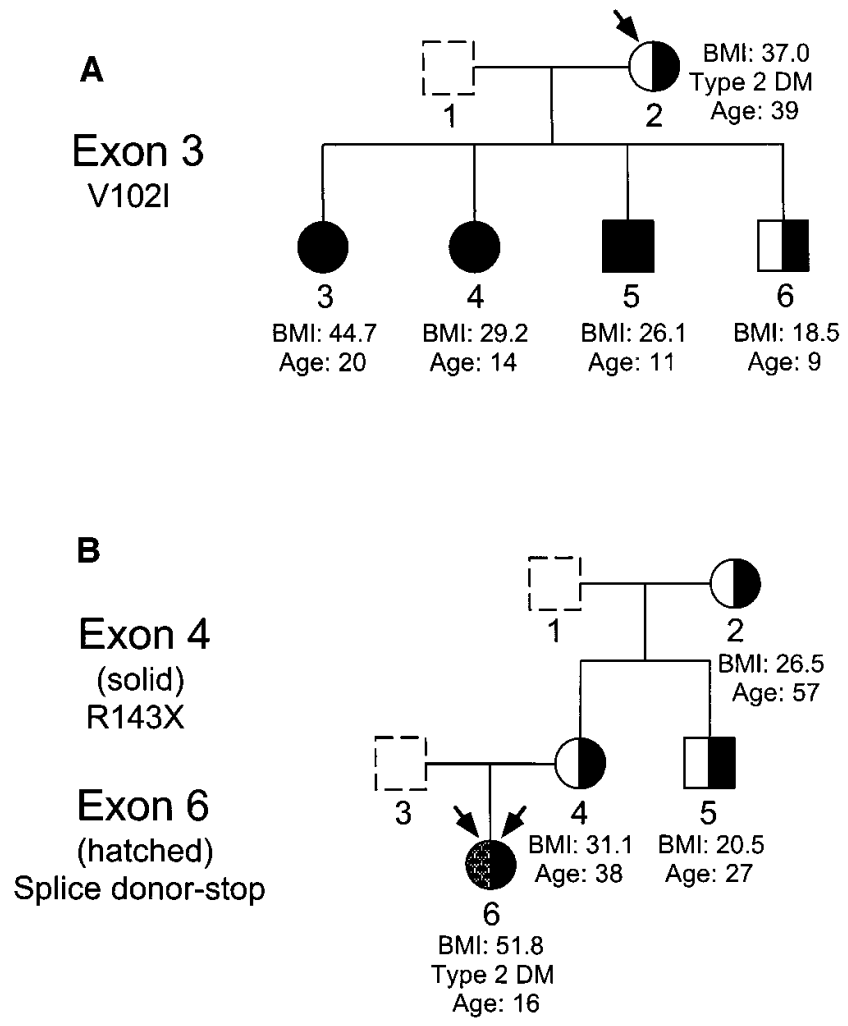

Figure 1. Pedigrees with mutations in the UCP3 gene. Interrupted lines designate individuals that were not available for study. Status for body mass index $(B M I)$ in $\mathrm{Kg} / \mathrm{m}^{2}$, Type 2 Diabetes Mellitus $(D M)$, and age are indicated. $(A)$ Pedigree with the V102I polymorphism. The filled circles and square represent homozygosity. Individuals 3-6 were not diabetic. The proband is indicated by an arrow. $(B)$ Pedigree with the R143X and exon 6-splice-donor mutation and polymorphism, respectively. The compound heterozygous proband is indicated by a double arrow. The diabetes status of individuals 2, 4, and 5 is not known. 
Wild type $\quad$ Mutant

A

\section{Exon 3 \\ G304A \\ V102I}
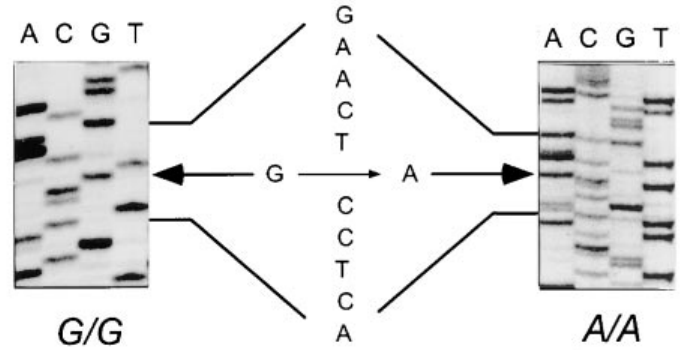

B

\section{Exon 4}

C427T

$\mathrm{R} 143 \mathrm{X}$

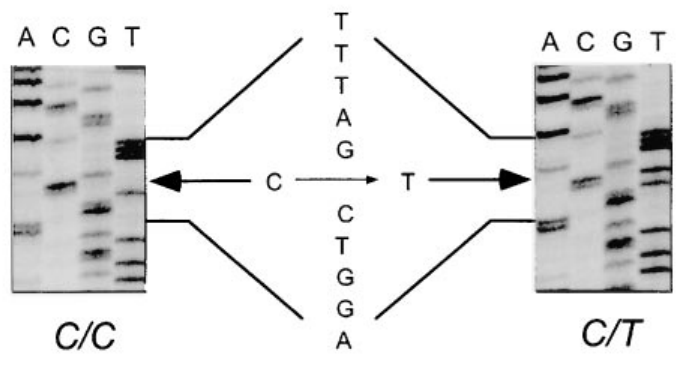

C

\section{Exon 6}

\section{Ggt $\longrightarrow$ Gat Splice donor-stop}

antisense

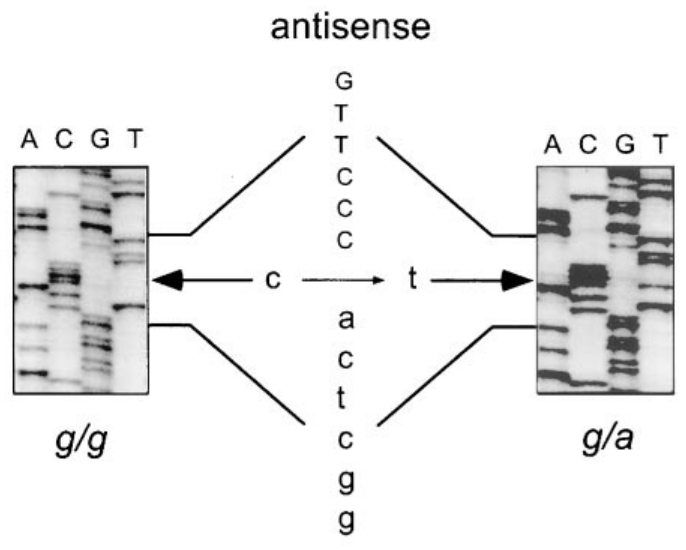

antisense
Figure 2. DNA sequence and mutation screening in the UCP3 gene. Wild-type sequences are shown on the left and mutant sequences are shown on the right in each panel. Two arrows pointing in opposite directions show the position of each mutation and the corresponding wild-type nucleotide. The genotype is shown italicized underneath each sequencing gel. $(A)$ Heterozygous polymorphism, V102I, in exon 3, resulting in V102I amino acid substitution. (B) Heterozygous mutation, R143X, in exon 4 , introducing a premature stop codon at residue 143. (C) Heterozygous polymorphism, Ggt-Gat, at the splice-donor site of exon 6, resulting in loss of the splice junction and truncation of the protein product at the first tga stop codon of the adjacent intron. Sequencing was performed with the reverse primer, and the sequence is read in the antisense form. in any individual in this population. However, examination in 280 African Americans revealed that 4\% of the individuals were homozygous and $28 \%$ heterozygous for the polymorphism (Table I). The V102I polymorphism was also assessed in a cohort of 180 members of the Mende tribe from Sierra Leone. $3 \%$ of the population was found to be homozygous for $A / A$, and $21 \%$ of the population was $G / A$ heterozygous (Table I). A $\chi^{2}$ test of homogeneity $\left(\chi^{2}=3.1577, v=2, P=0.1871\right)$ indicated that the genotype distribution and allele frequencies (Table I) were similar in the African American and Mende populations.

In a different proband, a heterozygous missense mutation (C427T) was identified in exon 4 of UCP3 (Fig. 2 B), resulting in introduction of a premature stop codon at residue 143 (R143X) in the third, matrix-orientated, loop (Fig. 3). In addi- tion, a heterozygous polymorphism (guanine to adenine) was identified in the same patient at the splice donor site of exon 6 (Ggt-Gat), resulting in loss of the splice junction and premature termination of the protein product (Fig. $2 C$ ) in the sixth, matrix-orientated, loop (Fig. 3). Coincidentally, any putative protein resulting from this mutation would be identical to that encoded by the short transcript of $U C P 3 \mathrm{mRNA}\left(U C P 3_{\mathrm{S}}\right)$.

Pedigree analysis (Fig. $1 B$ ) and DNA sequence determination of family members showed that the R143X mutation was transmitted to the compound heterozygous proband from the grandmother, through the mother, in typical Mendelian fashion. The heterozygous polymorphism at the exon 6-splice donor junction (Ggt-Gat) was not detected in the maternal lineage and must have been transmitted from the father (paternal DNA was not available for analyses) or, less likely, may have 
A

Nucleotide mutations

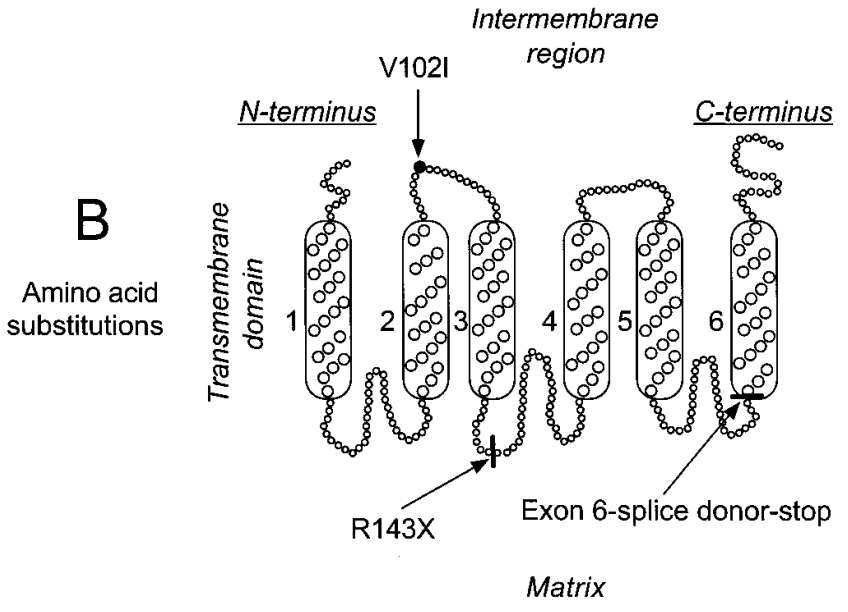

Figure 3. Schematic representation of the $U C P 3$ gene and protein product depicting the relative position of the mutations. (A) UCP3 gene structure and organization indicating the positions of the mutation and polymorphisms in exons $3-6$. $\mathrm{TGA}_{\mathrm{S}}$ and $\mathrm{TGA}_{\mathrm{L}}$ are the corresponding stop codons for $U C P 3_{\mathrm{S}}$ and $U C P 3_{\mathrm{L}}$. (B) Putative topology of the $U C P 3$ protein in the inner mitochondrial membrane (based on hydrophobicity analyses and available data for $U C P 1)(21)$ and position of the mutation and polymorphisms. The six transmembrane domains are numbered (1-6).

arisen spontaneously. Muscle tissue was not available for mRNA and protein isolation. An additional cohort of 168 individuals comprising both African Americans and Caucasians was examined for the presence of the two nucleotide changes. The R143X mutation was not detected in any other individual in either racial group. The exon 6-splice donor-stop mutation, however, was detected in African-American subjects but not in Caucasians. DNA samples from Gullah African Americans and the Mende tribe showed an identical allele frequency ( $\mathrm{G}$, $90 \%$ and A, 10\%) (Table I). No homozygous subjects for the polymorphism (a/a) were detected in 287 Gullah African Americans, and only three homozygotes were identified in 192 subjects of the Mende tribe (Table I). Haplotype analysis of the two polymorphisms (V102I, and exon 6-splice Ggt-Gat) was performed and showed that the two genotypes were independent $(P=0.521)$.

To examine for a potential direct role of the two polymorphisms on obesity and type 2 diabetes, related quantitative traits were assessed as a function of genotype. Among unrelated individuals, heterozygotes for the exon 6-splice donor mutation were found to have a $50 \%$ reduction in fat oxidation adjusted for lean body mass $(P=0.0188)$ and a marked elevation in the nonprotein respiratory quotient $(P=0.0079)$, compared with wild-type subjects (Table II). No significant differences were found between heterozygotes and wild-type individuals for BMI, percentage of body fat, and resting energy expenditure adjusted for lean body mass (Table II). The same type of analyses were performed for the V102I polymorphisms, but no significant differences were identified between heterozygotes and wild-type individuals for any of the aforementioned quantitative traits. The African-American population studied has a high prevalence of obesity; therefore, the possibility that this could mask a potential effect of $U C P 3 \mathrm{mu}-$ tations on BMI was also examined. To explore this possibility, genotype frequencies for the exon 6-splice donor polymorphism $(g / g$ versus $g / a)$ were compared in severely obese $(\mathrm{BMI}=$ $38, n=71)$ and lean (BMI $=26, n=49)$ subgroups. The frequency of the $g / a$ genotype was nearly twice as high $(P=0.04)$ in obese $(30 \%)$ compared with lean $(16 \%)$ individuals.

\section{Discussion}

A mutation (R143X) and two missense polymorphisms (V102I, Ggt-Gat at the exon 6-splice donor) in the UCP3 gene were identified in two severely obese probands. The V102I polymorphism was detected in a 20 -yr-old homozygous female with BMI of 44.7. The R143X mutation and the exon 6-splice polymorphism were detected in a 16-yr-old compound heterozygous proband with a BMI of 51.8. Pedigree analysis showed that these genic variants were transmitted in a typical Mendelian fashion, although they were not consistently associated with obesity in other family members. For example, only one

Table I. Genotype and Allele Frequencies

\begin{tabular}{|c|c|c|c|c|c|c|c|c|}
\hline & \multicolumn{4}{|c|}{ V102I* } & \multicolumn{4}{|c|}{ Exon 6-splice donor* } \\
\hline & $G / G$ & $G / A$ & $A / A$ & $\begin{array}{c}\text { Allele } \\
\text { frequency }\end{array}$ & $g / g$ & $g / a$ & $a / a$ & $\begin{array}{c}\text { Allele } \\
\text { frequency }\end{array}$ \\
\hline \multirow[t]{2}{*}{ Gullah } & $68 \%$ & $28 \%$ & $4 \%$ & $G: 82 \%$ & $80 \%$ & $20 \%$ & & $g: 90 \%$ \\
\hline & $(191)^{+}$ & $(78)$ & $(11)$ & $A: 18 \%$ & $(230)$ & $(57)$ & $(0)$ & $a: 10 \%$ \\
\hline \multirow[t]{2}{*}{ Mende } & $76 \%$ & $21 \%$ & $3 \%$ & $G: 87 \%$ & $82 \%$ & $16 \%$ & $1 \%$ & $g: 90 \%$ \\
\hline & $(137)$ & $(38)$ & $(5)$ & $A: 13 \%$ & $(158)$ & $(31)$ & (3) & $a: 10 \%$ \\
\hline
\end{tabular}

Genotype and allele frequencies for the V102I and exon 6-splice donor-stop polymorphisms in the UCP3 gene of Gullah-Speaking African Americans and in the Mende Tribe of Sierra Leone. ${ }^{*}$ Genotype frequencies conform to Hardy-Weinberg equilibrium $(P=$ NS $)$; ${ }^{+}$Sample sizes are shown in parenthesis. 
Table II. Effects of the Exon 6-Splice Donor-stop

Polymorphism on Quantitative Traits Relevant to Body Weight and Type 2 Diabetes in the Gullah

African-American Population

\begin{tabular}{lccrl}
\hline & \multicolumn{4}{c}{ Exon 6-splice donor } \\
\cline { 2 - 5 } & Mean \pm SEM & Mean \pm SEM & DF & $P$ value \\
\hline & $g / g$ & $g / a$ & & \\
BMI & $33.1 \pm 0.7$ & $34.1 \pm 1.0$ & 175 & 0.4975 \\
\% B. FAT & $29.8 \pm 0.8$ & $31.5 \pm 1.4$ & 144 & 0.3130 \\
FGLU & $146.3 \pm 11.5$ & $126.4 \pm 22.9$ & 52 & 0.5018 \\
RQ & $0.836 \pm 0.01$ & $0.905 \pm 0.03$ & 23 & $0.0164^{*}$ \\
NPRQ & $0.841 \pm 0.01$ & $0.933 \pm 0.05$ & 23 & $0.0079^{* *}$ \\
FATOX/LBM & $1.2 \pm 0.09$ & $0.6 \pm 0.25$ & 23 & $0.0188^{*}$ \\
REE/LBM & $28.3 \pm 0.5$ & $30.1 \pm 3.0$ & 23 & 0.7299 \\
& & & & \\
\hline
\end{tabular}

Analyses of the exon 6-splice donor polymorphism with various obesity- and Type 2 Diabetes-related phenotypic measurements. SEM, standard error of the mean; DF, degrees of freedom (DF, $\mathrm{N}_{1}+\mathrm{N}^{2}-2$ ); BMI, body mass index $\left(\mathrm{kg} / \mathrm{m}^{2}\right) ; \%$ B. FAT, percentage of body fat; FGLU, fasting glucose ( $\mathrm{mg} / \mathrm{dl})$; RQ, respiratory quotient; NPRQ, nonprotein RQ; FATOX/LBM, fat oxidation adjusted for lean body mass $(\mathrm{g} / \mathrm{kg} / 24 \mathrm{~h}) ; \mathrm{REE} / \mathrm{LBM}$, resting energy expenditure adjusted for lean body mass $(\mathrm{kcal} / \mathrm{kg} / 24 \mathrm{~h})$ ]; $*$ Significant values $(P<0.05)$ by Student's $t$ test; **Significant value $(P<0.005)$ by Student's $t$ test.

of the three homozygous family members was severely obese $(\mathrm{BMI}=44.7)$. Even so, BMI increased as a function of age in this family; in the homozygous siblings, BMI was 26.1 in the 11-yr-old son, 29.2 in the 14-yr-old daughter, and 44.7 in the 20-yr-old daughter. In the other pedigree, the R143X mutation was associated with obesity $(\mathrm{BMI}=31.1)$ in only one of three heterozygous family members. However, morbid obesity $(\mathrm{BMI}=51.8)$ was observed in the R143X/exon 6-splice compound heterozygous proband. Thus, homozygosity or compound heterozygosity may be required for predictable development of obesity, probably in conjunction with chronic environmental/dietary pressures. To date, only one other missense mutation (G84S) has been reported in the human $U C P 3$ gene, present in one lean, nondiabetic, Danish Caucasian in a cohort of 380 young healthy subjects (21).

Upon examination of African-American and Caucasian populations, we found the two polymorphisms exclusively in African Americans with allele frequencies of $18 \%$ (V102I) and $10 \%$ (exon 6-splice). When obesity- and Type 2 Diabetesrelated quantitative traits were assessed, heterozygotes for the exon 6-splice donor polymorphism were found to have only $50 \%$ the capability to oxidize fat $(P=0.0188)$ and had significantly elevated respiratory quotients $(P=0.0079)$ under basal conditions. The heterozygous exon 6-splice polymorphism was not associated with BMI or percentage of body fat. However, because the respiratory quotient represents a more proximal function of $U C P 3$ in the mitochondria, the impact of the polymorphism became evident even in the heterozygous state. An emerging view of $U C P 3$ function is that the transporter shuttles anionic free fatty acids (FFA) out of mitochondria, where protons are added to them and then they return to the mitochondrial matrix as neutral FFAs (22-24). This action could alter the distribution of fatty acids between the mitochondrial matrix and cytosol and, thus, affect availability of fatty acids for oxidation. It is noteworthy that the African-American population studied here has an overall high prevalence of obesity. These high levels of obesity, however, could be masking the potential effect of $U C P 3$ polymorphisms or mutations on BMI. To explore this possibility, the two genotype frequencies $(\mathrm{g} / \mathrm{g}$ versus $g / a$ ) in the African-American cohort were compared among severely obese (upper quartile) and lean subgroups (lower quartile). The $g / a$ genotype was found to be nearly twice as frequent in obese versus lean individuals $(P=0.04)$. Therefore, the data presented here also establish a relationship between the exon 6-splice polymorphism with the development of severe obesity in African Americans. The V102I heterozygous polymorphism was also examined for possible relationships with the aforementioned traits as well as genotype frequencies in obese versus lean individuals, but no significant correlations were found.

An effect of the UCP3 exon 6-splice donor polymorphism to reduce fat oxidation would predictably promote fat storage and provide a mechanism by which UCP3 mutations could predispose to obesity. Indeed, increased respiratory quotient (RQ) and low fat oxidation have previously been shown to be risk factors for future weight gain and the development of obesity $(25,26)$. Elevation of circulating FFA in rats induced a significant increase in skeletal muscle $U C P 3$ expression analogous to increased $U C P 3$ expression observed during fasting (27). Such induction of $U C P 3$ may enhance utilization of FFAs as fuel or help maintain the mitochondrial proton gradient necessary for oxidative ATP phosphorylation during fasting (27). Carriers of the exon 6-splice donor polymorphism had significantly reduced basal fat oxidation and elevated RQ, suggesting a predilection toward carbohydrate oxidation and storage of fat. This alteration implicates, for the first time, a role for $U C P 3$ in macronutrient fuel partitioning. However, more rigorous structure-function analyses are necessary to determine the impact of gene variation on $U C P 3$ function and to delineate the role of $U C P 3$ in human metabolism.

Emphasis should be placed on the fact that the two polymorphisms (V102I and exon 6-splice) were not detected in Caucasian Americans. It should also be pointed out that similar genotype and allele frequencies were observed in the Gullah-speaking African Americans that live off the coast of South Carolina $(28,29)$ and in the Mende tribe of Sierra Leone (Table II). The Gullah population is characterized by a high incidence of obesity and Type 2 Diabetes (30) and relative genetic homogeneity, with Caucasian admixture estimated at less than $5 \%$ (28). Cultural, historical, and linguistic records link Gullah-speaking African Americans with rice-cultivating tribes on the west coast of Africa, including the Mende tribe in Sierra Leone, in which the estimated prevalence of Type 2 Diabetes is $<4 \%$. It appears that both $U C P 3$ polymorphisms arose on the African continent and genotype frequencies have remained undisturbed in the two related populations. Recent experiments have shown that mRNA levels for both $U C P 2$ and $U C P 3$ in obese and lean individuals increase 2.5-fold during fasting, suggesting a role for the two genes in metabolic adaptation to fasting (31). Therefore, this polymorphism conceivably could have arisen in the Mende tribe (or elsewhere in sub-Saharan Africa) to alter $U C P 3$ function in a manner that promotes fat storage during food abundance and increases survivability during famine. This "thrifty" mechanism, however, may adversely lead to progressive obesity and diabetes in such a highly adapted population when members are chronically ex- 
posed to a high fat diet, as is the case for the Gullah African Americans.

Based on the putative topology of $U C P 3$, the missense amino acid substitutions were located in the third, matrixorientated, extramembranous loop (R143X); the first, cytosolorientated, loop (V102I); and the sixth, matrix-orientated, loop (Ggt-Gat, exon 6-splice donor-stop) (1, 32, 33). The R143X mutation and exon 6-splice junction polymorphism introduce premature termination codons and, predictably, would have a profound impact on protein function. The V102I polymorphism in exon 3 also has the potential to affect the secondary structure of the protein. Based on hydrophobicity and the segment singlet and pair preferences for the $\alpha$ helix or $\beta$ strand (34), the V102I polymorphism abolishes a predicted $\beta$-strand segment and introduces a new $\alpha$ helix. Moreover, the valine residue in the V102I polymorphism and the arginine residue in the R143X mutation may have significant functional properties, given that they are completely conserved in all uncoupling proteins described to date, in all species, including the plant UCPs (alignments not shown). The exon 6-splice polymorphism results in loss of the sixth transmembrane domain and the potential purine nucleotide binding domain (PNBD) at the $\mathrm{C}$ terminus of the protein. Binding of purines to PNBD is known to control coupling efficiency of $U C P 1$ and to induce conformational changes (1). Such loss of the PNBD and conformational shape in $U C P 3$ could perhaps influence the functional role of UCP3 to regulate lipids as fuel substrates and affect the requirement of skeletal muscle tissue for lipids during food deprivation (35).

In summary, a mutation (R143X) and the two polymorphisms (V102I, exon 6-splice donor) were detected in individuals with early-onset severe obesity and Type 2 Diabetes. Furthermore, subjects heterozygous for the exon 6-splice donor-stop polymorphism had markedly reduced fat oxidation and a high respiratory quotient, implicating a role for UCP3 in fuel partitioning in African Americans. Severely obese individuals exhibited a significantly higher frequency of this polymorphism, consistent with observations that low fat oxidation/high RQ are risk factors for the development of obesity. The detection of multiple polymorphisms in AfricanAmerican patients indicates that $U C P 3$ potentially constitutes an important obesity/diabetes gene in this racial group.

\section{Acknowledgments}

The authors wish to thank Richard Peterson of the core sequencing facility of the General Clinical Research Center at the Medical University of South Carolina (RR0-0170), Dr. Dennis Watson for helpful discussions, and Barbara Wojciechowski and David C. McLean, Jr. for help in statistical analyses. The authors are indebted to all the staff and participating nurses in Project Sugar for their field work on the Sea Islands of South Carolina and to participating Sea Island families. The authors also greatly appreciate the participation of staff and volunteers in Sierra Leone and express their gratitude to Penny Wallace (RN, MSN) and Elizabeth Ganaway (RN) for their help in the recruitment and study of research volunteers.

The work was supported by grants to W.T. Garvey from the National Institutes of Health (DK-38765 and DK-47461) and the Department of Veteran Affairs Research Service. The work was facilitated by a grant to the Medical University of South Carolina from the W.M. Keck Foundation (Los Angeles, CA) in support of the Sea Island Family Project and Project Sugar. S.M. Willi is the recipient of a National Institutes of Health Clinical Associate Physician Award (3MO1RR01070-20S2).

\section{References}

1. Boss, O., S. Samec, A. Paolini-Giacobino, C. Rossier, A. Dulloo, J. Seydoux, P. Muzzin, and J.-P. Giacobino. 1997. Uncoupling protein-3; a new member of the mitochondrial carrier family with tissue-specific expression. FEBS. 408:39-42.

2. Gong, D-W., Y. He, M. Karas, and M. Reitman. 1997. Uncoupling protein-3 is a mediator of thermogenesis regulated by thyroid hormone, $\beta 3$-adrenergic agonists and leptin. J. Biol. Chem. 272:24129-24131.

3. Vidal-Puig, A., G. Solanes, D. Grujic, J.S. Flier, and B.B. Lowell. 1997. $U C P 3$ : an uncoupling protein homologue expressed preferentially and abundantly in skeletal muscle and brown adipose tissue. Biochem. Biophys. Res. Commun. 235:79-82.

4. Silva, J.E., and R. Rabelo. 1997. Regulation of the uncoupling protein gene expression. Eur. J. Endocrinol. 136:251-264.

5. Cassard, A.-M., F. Bouillaud, M.-G. Mattei, E. Henz, S. Raimbault, M. Thomas, and D. Ricquier. 1990. Human uncoupling protein gene: structure, comparison with rat gene and assignment to the long arm of chromosome 4.J. Cell. Biochem. 43:255-264.

6. Fleury, C., M. Neverova, S. Collins, S. Raimbault, O. Champigny, C. Levi-Meyrueis, F. Bouillaud, M.F. Seldin, R.S. Surwit, D. Ricquier, et al. 1997. Uncoupling protein-2: a novel gene linked to obesity and hyperinsulinemia. Nat. Genet. 15:269-272.

7. Solanes, G., A. Vidal-Puig, D. Grujic, J.S. Flier, and B.B. Lowell. 1997. The human uncoupling protein-3 gene: genomic structure, chromosomal localization and genetic basis for short and long form transcripts. J. Biol. Chem. 272: 25433-25436.

8. Argyropoulos, G., A.M. Brown, R. Peterson, D.K. Watson, and W.T. Garvey. 1998. Structure and organization of the human uncoupling protein 2 gene and identification of a common biallelic variant in Caucasians and African-Americans. Diabetes. 47:658-687.

9. Larkin, S., E. Mull, W. Miao, R. Pittner, K. Albrandt, C. Moore, A. Young, M. Denaro, and K. Beaumont. 1997. Regulation of the third member of the uncoupling protein family, UCP3, by cold and thyroid hormone. Biochem. Biophys. Res. Commun. 240:222-227.

10. Matsuda, J., K. Hosoda, H. Itoh, C. Son, K. Doi, T. Tanaka, Y. Fukunaga, G. Inoue, H. Nishimura, Y. Yoshimasa, et al. 1997. Cloning of rat uncoupling protein-3 and uncoupling protein-2 cDNAs: their gene expression in rats fed high-fat diet. FEBS. 418:200-204.

11. Surwit, R.S., S. Wang, A.E. Petro, D. Sanchis, S. Raimbault, D. Ricquier, and S. Collins. 1998. Diet-induced changes in uncoupling proteins in obesity-prone and obesity-resistant strains of mice. Proc. Natl. Acad. Sci. USA. 95: 4061-4065.

12. Bouchard, C., L. Perusse, Y.C. Chagnon, C. Warden, and D. Ricquier. 1997. Linkage between markers in the vicinity of the uncoupling protein 2 gene and resting metabolic rate in humans. Hum. Mol. Genet. 6:1887-1889.

13. Zhang, Y., R. Proenca, M. Maffei, M. Barone, L. Leopold, and J.M. Friedman. 1994. Positional cloning of the mouse obese gene and its human homologue. Nature. 372:425-432.

14. Friedman, J.M. 1997. The alphabet of weight control. Nature. 385:119120.

15. Montague, C.T., I.S. Farooqi, J.P Whitehead, M.A. Soos, H. Rau, N.J. Wareham, C.P. Sewter, J.E. Digby, S.N. Mohammed, J.A. Hurst, C.H. Cheetham, A.R. Earley, A.H. Barnett, J.B. Prins, and S. O'Rahilly. 1997. Congenital leptin deficiency is associated with severe early-onset obesity in humans. Nature. 387:903-908.

16. Strobe, A., T. Issad, L. Camoin, M. Ozata, and A.D. Strosberg. 1998. A leptin missense mutation associated with hypogonadism and morbid obesity. Nat. Genet. 18:213-215.

17. Jackson, R.S., J.W. Creemers, S. Ohagi, M.L. Raffin-Sanson, L. Sanders, C.T. Montague, J.C. Hutton, and S. O'Rahilly. 1997. Obesity and impaired prohormone processing associated with mutations in the human prohormone convertase 1 gene. Nat. Genet. 16:303-306.

18. National Diabetes Data Group. 1979. Classification and diagnosis of diabetes and other categories of glucose intolerance. Diabetes. 28:1039-1057.

19. Peters, A.L., M.B. Davidson, D.L. Schriger, and V. Hasselblad. 1996. A clinical approach for the diagnosis of diabetes mellitus: an analysis using glycosylated hemoglobin levels. Meta-analysis research group on the diagnosis of diabetes using glycated hemoglobin levels. JAMA. 276:1246-1252.

20. Kennedy, A., T.W. Gettys, P. Watson, P. Wallace, E. Ganaway, Q. Pan, and W.T. Garvey. 1997. The metabolic significance of leptin in humans: genderbased differences in relationship to adiposity, insulin sensitivity and energy expenditure. J. Clin. Endocrinol. Metab. 82:1293-1300.

21. Urhammer, S.A., L.T. Dalgaard, T.I.A. Sorensen, A. Tybjaerg-Hansen, S.M. Echwald, T. Andersen, J.O. Clausen, and O. Pedersen. 1998. Organization of the coding exons and mutational screening of the uncoupling protein 3 gene in subjects with juvenile-onset obesity. Diabetologia. 41:241-244.

22. Jezek, P., D.E. Orosz, M. Modriansky, and K.D. Garlid. 1994. Transport of anions and protons by mitochondrial uncoupling protein and its regulation by nucleotides and fatty acids. A new look at old hypotheses. J. Biol. Chem. 269:26184-26190.

23. Murdza-Inglis, D.L., M. Modriansky, H.V. Patel, G. Woldegiorgis, K.B. 
Freeman, and K.D. Garlid. 1994. A single mutation in uncoupling protein of rat brown adipose tissue mitochondria abolishes GDP sensitivity of $\mathrm{H}^{+}$transport. J. Biol. Chem. 269:7435-7438.

24. Bienengraeber, M., K.S. Echtay, and M. Klingenberg. $1998 . \mathrm{H}^{+}$transport by uncoupling protein (UCP-1) is dependent on a histidine pair, absent in UCP-2 and UCP-3. Biochemistry. 37:3-8.

25. Ravussin, E. 1995. Metabolic differences and the development of obesity. Metabolism. 44:12-14.

26. Jakicic, J.M., and R.R. Wing. 1998. Differences in resting energy expenditure in African-American vs Caucasian overweight females. Int. J. Obes. 22: 236-242.

27. Weigle, D.S., L.E. Selfridge, M.W. Schwartz, R.J. Seeley, D.E. Cummings, P.J. Havel, J.L. Kuijper, and H. BeltrandelRio. 1998. Elevated free fatty acids induce uncoupling protein 3 expression in muscle. Diabetes. 47:298-302.

28. Chakraborty, R., M.I. Kamboh, M. Nwankwo, and R.E. Ferrell. 1992. Caucasian genes in American blacks: new data. Am. J. Hum. Genet. 50:145-155.

29. Pollitzer, W.S., E. Boyle, Jr., J. Cornoni, and K.K. Namboodiri. 1970. Physical anthropology of the Negroes of Charleston, S.C. Hum. Biol. 42:265279.
30. Eberhardt, M.S., D.T. Lackland, F.C. Wheeler, R.R. German, S.M. Teutsch. 1994. Is race related to glycemic control? An assessment of glycosylated hemoglobin in two South Carolina communities. J. Clin. Epidemiol. 47: 1181-1189.

31. Millet, L., H. Vidal, F. Andreelli, D. Larrouy, J.P. Riou, D. Ricquier, M. Laville, and D. Langin. 1997. Increased uncoupling protein-2 and -3 mRNA expression during fasting in obese and lean humans. J. Clin. Invest. 100:2665-2670.

32. Modriansky, M., D. Murdza-Inglis, H.V. Patel, K.B. Freeman, and K.D. Garlid. 1997. Identification by site-directed mutagenesis of three arginines in uncoupling protein that are essential for nucleotide binding and inhibition. $J$. Biol. Chem. 272:24759-24762.

33. Winkler, E., E. Wachtel, and M. Klingenberg. 1997. Identification of the $\mathrm{pH}$ sensor for nucleotide binding in the uncoupling protein from adipose tissue. Biochemistry. 36:148-155.

34. Solovyev, V.V., and A.A. Salamov. 1994. Predicting $\alpha$-helix and $\beta$-strand segments of globular proteins. CABIOS. 10:661-669.

35. Samec, S., Seydoux, J., and A.G. Dulloo. 1998. Role of UCP homologues in skeletal muscles and brown adipose tissue: mediators of thermogenesis or regulators of lipids as fuel substrate? FASEB. 12:715-724. 